\title{
o7. Uluslararası öğrencilerin Türkiye’nin somut olmayan kültürel mirasına yönelik farkındalıkları
}

Teymur EROL'

APA: Erol, T. (2021). Uluslararası öğrencilerin Türkiye'nin somut olmayan kültürel mirasına yönelik farkındalıkları. RumeliDE Dil ve Edebiyat Araştırmaları Dergisi, (23), 105-121. DOI: 10.2900o/rumelide.948303.

\section{$\ddot{O} \mathbf{z}$}

Dil öğretimi, kültürel küreselleşmenin önemli araçlarından biridir. Çünkü dil, kültürün hem bileşeni hem transfer aracıdır. Bu bağlamda Türkçenin yabancı dil olarak öğretimi, Türk kültürünün uluslararasılaşmasında uygun bir araç gibi görünmektedir. Kültürel küreselleşme eksenli bu çalışmada ileri düzeyde (C1) Türkçe bilen yabancı öğrencilerin somut olmayan kültürel miras listesinde yer alan kültürel ögelerimize yönelik bilgi ve farkındalıklarının belirlenmesi amaçlanmıştır. Genel tarama desenine göre tasarlanan çalışmada, Türkiye'nin UNESCO tarafından kabul edilen somut olmayan kültürel miras listesi veri toplama aracı işleviyle kullanılmış, toplam 41 katılımcıdan veri toplanmıştır. Katılımcıların kültürel ögelere yönelik farkındalıkları iki boyutta (görüntüsel gösterge ve sözel gösterge) ve üç düzeyde (habersizlik, nominal ve işlevsel düzey) ölçülmüştür. Elde edilen veriler betimsel analiz tekniğiyle incelenmiştir. Verilerin analizi sonucunda somut olmayan kültürel değerlerimizin dil öğretim süreçlerine yeterli düzeyde aktarılmadığı tespit edilmiştir. Somut olmayan kültürel miras listesinde yer alan ve çalışma kapsamına alınan kültürel unsurların tamamının görüntüsel göstergelerini işlevsel düzeyde anlayıp yorumlayabilen katılımc oranı yaklaşık \%8 civarında iken, sözel göstergeleri işlevsel düzeyde anlayıp yorumlayan katılımcı oranı yaklaşık \%4’tür. Bu sonuca göre ileri düzey Türkçe bildiği varsayılan uluslararası öğrencilerin, somut olmayan kültürel mirasımıza yönelik farkındalıkları düşüktür. Bir egemenlik göstergesi olarak dilin ve diplomatik bir araç olarak kültürün toplumsal ve siyasal olarak yeniden tanımlandıkları biçimleriyle Türkçe öğretiminde yeterli düzeyde yer alması gerektiği değerlendirilmektedir.

Anahtar kelimeler: Somut olmayan kültürel miras, yabancı dil olarak Türkçe öğretimi, kültür, kültürel küreselleşme, kültürel diplomasi

\section{Awareness of international students towards Turkey's intangible cultural heritage}

\begin{abstract}
Language teaching is one of the important tools of cultural globalization. Because language is both a component of culture and a means of transfer. In this context, teaching Turkish as a foreign language seems to be an appropriate tool for the internationalization of Turkish culture. It is aimed to determine foreign students knowledge and awareness of our cultural elements in the intangible cultural heritage list who can speak Turkish at advanced level. In study which designed as a general survey, list of Turkey's intangible cultural heritage used as a data collection tool, recognized by
\end{abstract}

Dr. Öğr. Gör., Kahramanmaraş Sütçü İmam Üniversitesi, TÖMER (Kahramanmaraş, Türkiye) erolteymur@gmail.com, ORCID ID: 0000-0003-1738-0858 [Araştırma makalesi, Makale kayt tarihi: 15.04.2021-kabul tarihi: 20.06.2021; DOI: 10.29000/rumelide.948303], ETIK: Kahramanmaraş Sütçü İmam Üniversitesi Sosyal ve Beşeri Bilimler Etik Kurulu, 24.03.2021, 2021/18.

RumeliDE Dil ve Edebiyat Araşttrmaları Dergisi Osmanağa Mahallesi, Mürver Ciçeği Sokak, No:14/8 Kadıköy - ISTANBUL / TÜRKIYE 34714 e-posta: editor@rumelide.com tel: +90 $5057958124,+902167730616$
Address

RumeliDE Journal of Language and Literature Studies

Osmanağa Mahallesi, Mürver Çiçeği Sokak, No:14/8

Kadıköy - ISTANBUL / TURKEY 34714

e-mail: editor@rumelide.com,

phone: +90 5057958124 , +90 2167730616 
UNESCO, data were collected from a total of 41 participants. Participants' awareness of cultural elements was measured in two dimensions (visual indicator and verbal indicator) and three levels (unawareness, nominal and functional level). The data obtained were analyzed using the descriptive analysis technique. As a result of the analysis of the data, it was determined that our intangible cultural values were not adequately transferred to language teaching processes. While the rate of participants who can understand and interpret the visual indicators of all cultural elements included in the intangible cultural heritage list at a functional level is around $8 \%$, the rate of participants who understand and interpret verbal indicators at a functional level is approximately $4 \%$. According to this result, the awareness of international students, who are assumed to know advanced Turkish, about our intangible cultural heritage is low. It is considered that language as an indicator of sovereignty and culture sovereignty and culture as a diplomatic tool should take place in Turkish teaching in their socially and politically redefined forms.

Keywords: Intangible cultural heritage, teaching Turkish as a foreign language, culture, cultural globalization, cultural diplomacy

\section{Giriş}

Temel dil becerilerinin doğru ve etkili kullanımı, sağlam bir gramer bilgisinin yanında, dile renk ve tat veren kültürel unsurlara hâkim olmayı, kültüre dayalı ritüelleri bilmeyi gerektirmektedir. Çünkü sesten cümleye kadar dilin içinde varlık bulan formlar, kültürel özelliklere göre anlam kazanabilmektedir. Sese dökülmeyen, sadece jest, mimik gibi işaret ve ikameler aracılığıyla ortaya çıan iletişim dili de çoğu zaman kültürel formların ürünüdür. Bu nedenle dil, kültürün ayrılmaz bir parçasıdır ve doğal olarak yaşamla çok sıkı ilişki içindedir (Kaplan, 1992: 160).

Dil; ulusları yansıtan, onları diğerlerinden farklı kılan kimliktir. Değer yargılarımızın ve davranış kalıplarımızın yaşam alanı dildir. Dil, kültürün bir bileşeni olarak ona hayat ve devamlılık veren, ondan soyutlanamayan bir vasitadır. Gökalp’in ifadesiyle (aktaran: Baltacığlu, 1964: 3) kültürü oluşturan değerlerden biridir. Dil aynı zamanda milli kültürün önemli bir parçası (Kavcar, 1987: 261), insanın ait olduğu toplumla kurduğu güçlü bir bağdır (Aksan, 1995: 8). Bu nedenle dil öğretimi kültür öğretimi olduğu gibi (Yüce ve Koçer, 2014: 481), bir toplumun dilde hayat bulan kültürel birikiminin başka bir topluma mensup kişilere aktarım sürecidir (Melanlığlu, 2008, 65).

Yaşadığımız zaman diliminde, kültür ve dil geleneksel tanımlarını aşan, toplumsal değişimlerden beslenerek yeniden anlam ve işlev kazanan, dolayısıyla sürekli olarak gelişen iki kavramdır. Gökalp’in (2019: 26) "bir milletin dinî, ahlaki, hukuki, muakalevi, bedii, lisani, iktisadi ve fenni hayatlarmin ahenktar bir mecmuası” olarak tanımladığı ve adına hars dediği kültür, modernite öncesi toplumların millilik vasfını vurgulayan bir kavramdır. Kültürle ilgili başvuru kaynaklarında (Akarsu, 1988; Güvenç, 1974; Kafesoğlu, 1998; Kaplan, 1992; Turhan, 1994) kavramın millilik vasfi sosyolojik bir terim olarak varlığını sürdürse de 1980'lerden itibaren birçok alanda olduğu gibi kültürün de küreselleşmesi, ona yüklenen geleneksel tanımların revize edilmesi ihtiyacını doğurmaktadır. Kültürel küreselleşme; modern değerlerle geleneksel normların, sembollerin ve söylemlerin bir arada var olmasını mümkün kılan, Batı kaynaklı kültürel kalıpların evrenselleşmesine uygun zemin hazırlarken yerel değerler ile geleneklerin yeniden canlanmasına imkân tanıyan çok boyutlu bir süreç karakteri taşımaktadır (Keyman, 2001: 8).

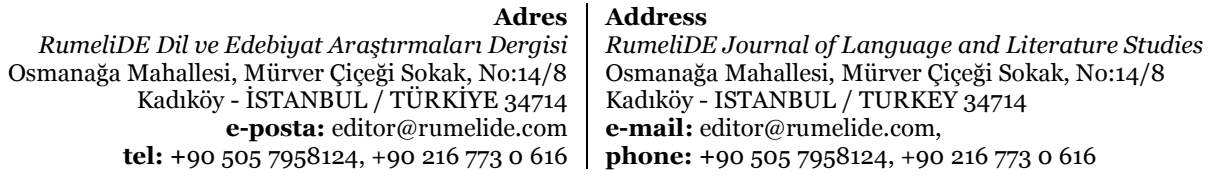

tel: +90 505 7958124, +90 2167730616 
Dil öğretimi, kültürel küreselleşmenin önemli araçlarından biridir (Kumaravadivelu, 2008: 46). Çünkü dil, kültürün hem bileşeni hem transfer aracıdır. Dil öğretimi aracılığıyla sağlanan kültür aktarımı, aslında bir topluma ait olan kültürel mirasın ve belki de kültürel sistemlerin nüfuz alanının genişletilmesidir. Başka bir deyişle ulusal düzeydeki kültürel formların tanzim edici gücünün uluslararasılaştırılmasıdır. Kültür ve kültürel sistemler sosyolojik olarak toplumu oluşturan değerler bütünüdür (Göçer, 2012: 50) ve aynı zamanda bu değerler siteminden beslenen bir çeşit güçtür (Swidler, 1995: 30). Bunun yanında kültürel normlar ve ritüeller toplumsal alanda düzeni sağlayan, toplumu oluşturan bireyleri belli semboller etrafında bir arada tutan güçlü bir otoritedir (Iriye, 1979: 117). Başta aile olmak üzere yakın çevrenin etkisiyle belirlenen kültürel kodlar nesiller arasındaki geçişkenlikle varlığını sürdüren, kültürün korunması ve kontrolüne dayalı bir egemenlik şeklidir. Dil öğretimi kültürel unsurların ve kültürel sistemlerin öğretimini içerdiğinden, bu faaliyet kültürel değer ve ritüellerin yanında, kültüre atfedilen düzenleyici ve kontrol edici gücün öğretimle transfer edilmesi olarak yorumlanabilir.

Kültürel küreselleşme bağlamında, kültür aktarımı gibi dil öğretimi de coğrafi olmayan egemenlik vasıtasıdır (Kachru, 1986: 123). Aslında dilin bizatihi kendisi sosyolojik olarak güç ve dolayısıyla egemen olma kavramlarıyla ilişkili olarak betimlenmektedir (Bruns, 1984; Janks, 2008; Wodak, 2012). $\mathrm{Bu}$ egemenlik bazen bireysel, bazen kitlesel, bazen siyasal nüfuzun kullanımı şeklinde tezahür edebilir. İçinde yaşadıkları toplumlarda, sosyolojik olarak, genel ve güçlü eğilimleri temsil edenler bireysel olarak kullandıkları dilde bile egemen bir söylem taşıyabilir. Bu söylem bireysel alandan daha geniş kitlelerin oluşturduğu topluluk dili olarak da karşımıza çıkabilir. Özellikle iktisadi ve siyasi gücün belli merkezler tarafından kontrol edildiği toplumlarda; benzer düşünceleri, kaygıları, tutum, inanç ve ilkeleri olan sosyal grupların dili veya üslupları bir hâkimiyet aracı olarak daha da belirginleşebilir (Bourdieu, 1991: 503). Toplumların tarihlerinde sözü edilen bu güç merkezlerine bağlı olarak egemen dil ve egemen söylem el değiştirebilir. Ulusal sınırlar içinde toplumsal dinamiklerle birlikte hareket eden dil ve kültür, uluslararası alanda, kültürel küreselleşme yüzüyle ve ait olduğu toplumun gücü nispetinde benzer eğilimler gösterebilir. Örneğin siyasi, askeri ve iktisadi bakımdan güçlü olan toplumların dil ve kültürleri de birer güç vasıtasına kolaylıkla dönüşebilir. Çünkü siyasi, askeri ve iktisadi güç kültürel gücü besleyebilir, birindeki egemenlik alanı diğerlerine kolaylıkla yer açabilir.

Kültürel küreselleşmeyle ilişkilendirilebilecek önemli kavramlardan biri de kültürel diplomasidir. Kültür kavramını oluşturan maddi ve manevi değerlerin, yaşam biçiminin, estetik zevkin, duyuş ve düşünüş tarzının toplumlar arasında paylaşımını esas alan kültürel diplomasi, toplumları yakınlaştıran önemli bir etkileşim aracıdır (Purtaş, 2013: 2). Kavram, bir çeşit kültürel güçtür ve uluslararası ilişkilerde yumuşak güç olarak tanımlanır (Nye: 1990: 168). Küresel dünya düzeninde, kültürel diplomasinin çekirdeğini oluşturan kültürel ve dilsel güç, pratikte toplumlar arasında eşit düzeyli bir paylaşımdan ziyade, egemen olanın güçsüz olana bir dizi küresel acente vasıtasıyla kendinden olanı hâkim kılma, güçsüze "yumuşak" yoldan kendine ait olanı aktarma olarak görülebilir. Dil öğretiminde ve kültürün küreselleşmesinde British Council, Goethe Enstitüsü, Cervantes Enstitüsü, Fransız Kültür Merkezi, Konfüçyus Enstitüsü, Yunus Emre Enstitüsü yumuşak gücü temsil eden önemli kuruluşlar olarak dikkat çekmektedir.

Geçen yüzyllın sonlarından itibaren küresel aktörlerin toplumları homojenleştirici müdahalelerine, yerel ve milli olanı korumak için güçlü reflekslerle karşılık verildiği görülmektedir. UNESCO tarafından kabul edilen insanlı̆̆ın somut olmayan kültürel mirasının (SOKÜM) korunmasına dair sözleşme bu türden bir karşllk sayılabilir. Söz konusu sözleşme; "bir toplumun kendi kültürel kimliğinin bir parçası olarak gördüğü ve kuşaktan kuşağa aktarmak suretiyle günümüze kadar

Adres Address

RumeliDE Dil ve Edebiyat Araşttrmaları Dergisi $\quad$ RumeliDE Journal of Language and Literature Studies Osmanağa Mahallesi, Mürver Çiçeği Sokak, No:14/8 Osmanağa Mahallesi, Mürver Çiçeği Sokak, No:14/8 Kadıköy - İSTANBUL / TÜRKIYE 34714 Kadıköy - ISTANBUL / TURKEY 34714 e-posta: editor@rumelide.com e-mail: editor@rumelide.com, tel: +90 505 7958124, +90 2167730616 phone: +90 505 7958124, +90 2167730616 
getirdiği somut olmayan kültürel mirasların korumasına ve gelecek kuşaklara aktarmasına katkı sağlayacak yol, yöntem ve imkânları tanımlamaktadır." (Öcal, 2009: 8). Sözleşmede geçen SOKÜM kavramı, kültürel mirasın maddi (obje) unsurları yerine, maddi/somut olmayan unsurlarını "üreten, yaşatan ve kuşaktan kuşağa aktaran bilgi, gelenek ve birikimin bütün unsurlartyla korunması" (Öcal, 2013: 11) anlamına gelmektedir.

Kültürel değerlerin korunmasında sürdürülebilir, bütünleşik ve akılcı koruma yaklaşımlarına dayalı miras yönetiminde (Turgut Gültekin ve Uysal, 2018: 2032) ulusal ve uluslararası düzeyde bilinç ve farkındalık oluşturmanın önemli olduğu değerlendirilmektedir. $\mathrm{Bu}$ farkındalığın ülke içinde oluşturulmasında, her seviyedeki eğitim ve öğretim faaliyeti; uluslararası düzeyde oluşturulmasında ise Türkçe öğretimi uygun görünmektedir. Çünkü dilin öğrenilmesi ve kullanılması, kültürün de öğrenilmesi ve bilinmesi demektir (Kolaç, 2009: 21). Bu anlayıştan hareketle yapılan çalışmalarda (Akcaoğlu, 2017; Altınok, 2020; Karakoç Öztürk, 2020; Moralı ve Öner, 2019; Okur, 2013; Ünveren Kapanadze, 2018; Yıldız ve Ceran, 2020) genel olarak SOKÜM’ün Türkçe ders kitaplarına yansıma biçimine yoğunlaştığı görülmektedir. Hâlbuki ders kitaplarına yansıyan ve ders kitapları aracılığıyla aktarılan kültürel ögelerin uluslararası öğrencilerde hangi düzeyde farkındalık veya bilinç oluşturduğu, Türkçenin yabancı dil olarak öğretiminde hedeflenen kazanımlar açısından oldukça önemlidir. Bu nedenle çalışmada, ileri düzeyde (C1) Türkçe bilen uluslararası öğrencilerin SOKÜM listesinde yer alan kültürel değerlerimize yönelik bilgi ve farkındalıklarının belirlenmesi amaçlanmıştır. Bu çerçevede çalışmanın problem cümlesi "Uluslararası öğrenciler, somut olmayan kültürel mirasımıza yönelik hangi düzeyde bilgi ve farkındalık sahibidir?” şeklinde ifade edilmiş ve bu ana problem altında aşağıdaki alt problemlere cevap aranmıştır:

İleri düzey Türkçe bilen uluslararası öğrenciler SOKÜM listesinde yer alan;

1. Meddahlık Geleneği’ne,

2. Mevlevi Sema Törenleri'ne,

3. Âşılklk Geleneği’ne,

4. Karagöz Geleneği’ne,

5. Geleneksel Sohbet Toplantıları'na,

6. Kırkpınar Yağlı Güreş Festivali’ne,

7. Alevî-Bektaşî Ritüeli Semah’a,

8. Mesir Macunu Festivali’ne yönelik hangi düzeyde farkındalık sahibidir?

\section{Yöntem}

$\mathrm{Bu}$ araştırmada, Türkçeyi yabancı dil olarak öğrenenlerin Türkiye'nin somut olmayan kültürel mirasına yönelik genel bilgi ve farkındalık düzeylerini belirlemek amacıyla genel tarama modeli kullanılmıştır. Genel tarama modelleri, belli bir evren hakkında genel bir çıkarımda bulunmak için evrenin tümü veya onu temsil edebilecek bir grup, örnek ya da örneklem üzerinde yapılan tarama işlemidir (Karasar, 2019: 111).

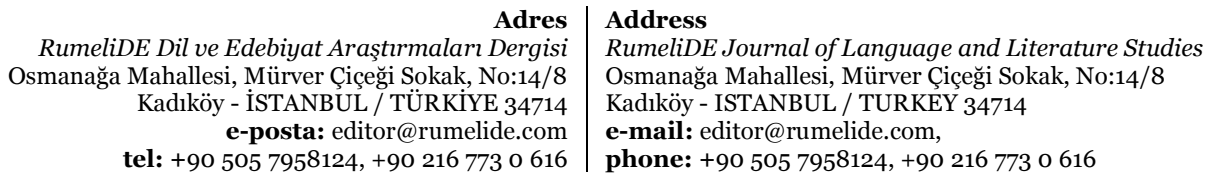




\section{1. Çalışma grubu}

Araştırma; etik kurul izni alındıktan sonra, Türkiye'nin farklı illerindeki üniversitelerin bünyesinde faaliyet gösteren Türkçe Öğretim Uygulama ve Araştırma Merkezlerinden (TÖMER) C1 düzeyinde yeterlik belgesi almış 41 katılımcıyla gerçekleştirilmiştir. Katılımcıların 15’i kadın, 26'sı erkektir. Çalışma grubuna ait bilgiler Tablo 1'de verilmiştir:

Tablo 1. Çalışma Grubu

\begin{tabular}{|c|c|c|c|c|}
\hline & & $\mathbf{n}$ & $\%$ & Katılımcilar \\
\hline \multirow{8}{*}{ Milliyet } & Suriye & 12 & 29,3 & $\mathrm{~K}_{1}, \mathrm{~K}_{2}, \mathrm{~K}_{3}, \mathrm{~K}_{4}, \mathrm{~K}_{5}, \mathrm{~K} 6, \mathrm{~K}_{7}, \mathrm{~K} 8, \mathrm{~K} 9, \mathrm{~K} 10, \mathrm{~K} 11, \mathrm{~K} 12$ \\
\hline & Endonezya & 7 & 17,1 & $\mathrm{~K} 13, \mathrm{~K} 14, \mathrm{~K} 15, \mathrm{~K} 16, \mathrm{~K} 17, \mathrm{~K} 18, \mathrm{~K} 19$ \\
\hline & Cibuti & 5 & 12,2 & K2O, K21, K22, K23, K24 \\
\hline & Somali & 5 & 12,2 & K25, K26, K27, K28, K29 \\
\hline & Misir & 4 & 9,8 & $\mathrm{~K}_{30}, \mathrm{~K}_{31}, \mathrm{~K}_{32}, \mathrm{~K}_{33}$ \\
\hline & Yemen & 3 & 7,3 & $\mathrm{~K}_{34}, \mathrm{~K}_{35}, \mathrm{~K}_{36}$ \\
\hline & Fas & 3 & 7,3 & $\mathrm{~K}_{37}, \mathrm{~K}_{3} 8, \mathrm{~K}_{39}$ \\
\hline & Afganistan & 2 & 4,9 & $\mathrm{~K} 40, \mathrm{~K} 41$ \\
\hline \multirow{2}{*}{ Türkiye'de Bulunma Süresi } & $2-3$ yll & 29 & 70,7 & \\
\hline & 4 yıl ve üzeri & 12 & 29,3 & \\
\hline
\end{tabular}

Çalışma grubunda yer alan ve Türkiye'ye sekiz farklı ülkeden gelen katılımcıların çok uluslu olmasına gayret edilmiştir. Bu amaçla, katılımcı belirlenirken amaçlı örnekleme yöntemlerinden maksimum çeşitlilik örneklemesi ile ölçüt örnekleme yöntemine başvurulmuştur. Maksimum çeşitlilik örneklemesi, görece daha küçük bir grup oluşturmak suretiyle problemin ele alınmasında taraf olduğu değerlendirilen kişileri olabildiğince çeşitlendirmeyi amaçlamaktadır. Ölçüt örneklemede ise önceden belirlenen koşulları karşılama durumuna bağlı olarak belli bir grubun seçilmesidir (Yıldırım ve Şimşek, 2016: 119).

Çalışmada, SOKÜM listesinde yer alan kültürel ögelere ilişkin görüntüsel ve sözel gösterge bilgileri çok uluslu, çok kültürlü bir örneklemle yansıtılmıştır. Katılımcıların TÖMER'den C1 düzeyinde sertifika almış olması temel ölçüt olarak belirlenmiştir. Bu koşulu karşılayan ve gönüllü olarak katılabileceğini beyan edenler çalışma grubunu oluşturmaktadır.

\subsection{Verilerin toplanması ve analiz}

Yabancı dil olarak Türkçe öğrenenlerin SOKÜM’e yönelik bilgi ve farkındalık düzeylerini belirlemeyi amaçlayan bu araştırmada UNESCO tarafından farklı tarihlerde kabul edilen Türkiye'nin SOKÜM listesi görüşme formu işleviyle kullanılmıştır.

Katılımcıların SOKÜM listesindeki kültürel ögelere yönelik farkındalığı iki şekilde ölçülmüştür: kültürel ögenin görüntüsel göstergesine (görsel) ilişkin farkındalık, kültürel ögenin sözel göstergesine yönelik farkındalık. Görüntüsel gösterge belirttiği şeyi doğrudan temsil eden, canlandıran görüntüye dayalı bir fotoğraf ya da çizgisel anlatımlar (karikatürler) olabilir. Sözel göstergeler ise dilsel anlatımın tümünü kapsar (Günay, 2008: 2-4).

\footnotetext{
Adres $\mid$ Address

RumeliDE Dil ve Edebiyat Araşttrmaları Dergisi $\quad$ RumeliDE Journal of Language and Literature Studies Osmanağa Mahallesi, Mürver Çiçeği Sokak, No:14/8 Osmanağa Mahallesi, Mürver Çiçeği Sokak, No:14/8 Kadıköy - İSTANBUL / TÜRKIYE 34714 Kadıköy - ISTANBUL / TURKEY 34714 e-posta: editor@rumelide.com e-mail: editor@rumelide.com, tel: +90 505 7958124, +90 2167730616 phone: +90 505 7958124, +90 2167730616
} 
Hem UNESCO (2021) hem de Kültür ve Turizm Bakanlığının (2021) resmi verilerine göre Türkiye'nin SOKÜM listelerine kayıtlı 20 adet unsuru bulunmaktadır. Bunların bazıları çok ulusludur: "Nevruz (1), İnce Ekmek Yapımı ve Paylaşımı Geleneği: Lavaş, Katrıma, Jupka, Yufka (2), Bahar Bayramı Hıdırellez (3), Dede Korkut-Korkut Ata Mirası: Kültürü, Efsaneleri ve Müziği (4), Minyatür Sanatı (5), Geleneksel Zekâ ve Strateji Oyunu (6)" çok uluslu kültürel ögelerdir. Türkiye'nin farklı uluslarla birlikte sunduğu dosyalar sonucunda UNESCO tarafından kabul edilen ve SOKÜM listesine alınan bu unsurların ayırt edicilik vasfı taşımayacağı düşünülerek çalışma kapsamına alınmamıştır. Öte yandan veri toplama sürecinde, Türkiye'nin tekil olarak kaydettirdiği bazı kültürel öğelerin de çalışma grubunu teşkil eden katılımcılarda ayırt edicilik özelliği taşımadı̆̆ görülmüsstür. "Tören Keşkeği Geleneği (1), Türk Kahvesi ve Geleneği (2), Ebru: Türk Kâğıt Süsleme Sanatı (3), Geleneksel Çini Sanatı (4), Geleneksel Türk Okçuluğu (5) ve Islık Dili (6)" birçok katılımcının kendi toplumlarında karşılıkları olan kültürel ögelerdir. İslam medeniyeti içinde yer alan toplumların benzer formlarla yaşattığı, ancak farklı olarak isimlendirdiği kültürel ögeler -Karagöz hariç- çalışmaya dâhil edilmemiştir. Karagöz oyunu birkaç katılımcı tarafından kendi ana dillerindeki karşılığıyla ifade edilmiş olmakla birlikte, yukarıda sayılanlardan daha yüksek ayıt edicilik karakteri gösterdiğinden çalışmaya dâhil edilmiştir. Böylece 8 kültürel öge çalışma kapsamına alınmıştır.

Görüşmelerden elde edilen nitel veriler betimsel analiz yöntemiyle incelenmiştir. Bu kapsamda veriler önceden belirlenen temalara göre özetlenmiş ve yorumlanmıştır (Yıldırım ve Şimşek, 2016: 239). Yapılan analizde, SOKÜM’e yönelik üç farkındalık düzeyi (tematik çerçeve) belirlenmiştir:

Habersizlik düzeyi: Kültürel ögeyi bilmeme veya hiç duymama durumu.

Nominal farkındalık düzeyi: Kültürel ögenin nesnesini kültürel ögenin göstergeleriyle ilişkilendirebilme, kültürel ögenin isminden haberdar olma durumu. Belirli bir fotoğrafın, resmin, sözcüğün verilen kültürel unsurla ilgili olduğunu anlama.

İşlevsel farkındalık düzeyi: Kültürel ögeye ilişkin görüntüsel ve sözel göstergeleri doğru anlama ve yorumlama.

Bu farkındalık düzeyleri Pill ve Harding’in (2013: 383) okuryazarlık için yaptığı sınıflandırmadan uyarlanmıştır. Esasen katılımcıların SOKÜM'deki kültürel unsurlara ilişkin farkındalık düzeyi hedef dilin kültürüne ilişkin okuryazarlık olarak da değerlendirilebilir. Dolayısıyla katılımcının farkındalık düzeyi kültürel ögeye ilişkin okuryazarlık düzeyini ifade etmektedir.

Katılımcılardan elde edilen veriler öncelikle araştırmacı tarafından düzeylere dağıtılmış, daha sonra güvenirliği sağlamak amacıyla, Türkçe eğitimi alanında akademisyen olarak çalışan bir uzmandan görüş alınmıştır. Araştırmacı ile uzman görüşleri Miles ve Hubermann (1994: 64) formülü kullanılarak karşılaştırılmıştır. Miles ve Hubermann’a göre \%70'lik görüş birliği güvenilir bir sonuçtur. Araştırmacı ile uzman arasındaki küçük çaplı uyumsuzluklar ikinci bir değerlendirme sonucunda revize edilmiş ve tam uzlaşma sağlanmıştır. Daha sonra, SOKÜM’e yönelik farkındalık düzeyleri esas alınarak katılımcı görüşleri tekrarlanma sıklıklarına göre tablolaştırılmıştır. Düzenlenen veriler, katılımcıların cevaplarıyla desteklenerek açılanmış ve yorumlanmıştır. Alıntılarda katılımcılar "K1, K2,..K41" şeklinde tanımlanmıştır.

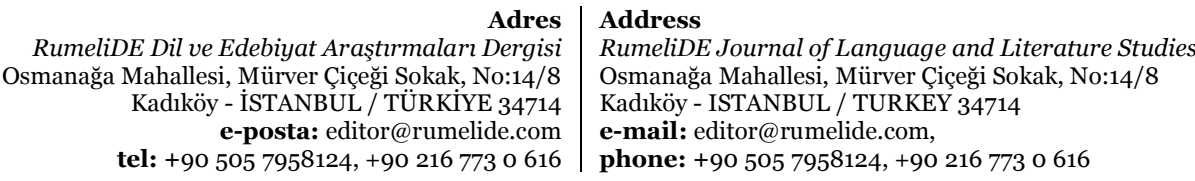




\section{Bulgular ve yorum}

SOKÜM listesinde bulunan sekiz kültürel ögeye ilişkin farkındalık düzeyi katılımcı cevaplarına göre belirlenmiştir. Görüntüsel gösterge ve sözel göstergeyle ilgili bilgisizlik "habersizlik" düzeyi olarak belirlenmiştir. Kültürel ögenin görüntüsel ve sözel göstergesine aşinalık durumu "nominal” düzey olarak isimlendirilmiştir. Kültürel ögenin görüntüsel ve sözel göstergesinin doğru biçimde anlaşllp ifade edilmesi "işlevsel" düzey olarak kabul edilmiştir. Katılımcıların cevaplarından elde edilen bulgular aşağıda tablolar halinde sunulmuştur:

\subsection{Birinci alt probleme ilişkin bulgular ve yorum}

İleri düzey Türkçe bilen uluslararası öğrencilerin Meddahlık Geleneği’ne yönelik farkındalıkları Tablo 2'de yer almaktadır.

Tablo 2. Katılımcıların Meddahlık Geleneği’ne Yönelik Farkındalıkları

\begin{tabular}{|c|c|c|c|c|}
\hline Kültürel Öge & $\begin{array}{l}\text { Farkındalık } \\
\text { Türü }\end{array}$ & $\begin{array}{l}\text { Farkındalık } \\
\text { Düzeyi }\end{array}$ & $\mathbf{n}$ & Katılımcılar \\
\hline \multirow{6}{*}{ Meddahlık } & \multirow{3}{*}{$\begin{array}{l}\text { Görüntüsel } \\
\text { Gösterge } \\
\text { Farkındalığı }\end{array}$} & Habersiz & 36 & $\begin{array}{l}\text { K1, K2, K3, K4, K5, K6, K8, K9, K10, K13, K14, K15, } \\
\text { K16, K17, K18, K19, K2O, K21, K22, K23, K24, K25, } \\
\mathrm{K}_{2} 6, \mathrm{~K}_{2} 8, \mathrm{~K}_{2} 9, \mathrm{~K}_{30}, \mathrm{~K}_{31}, \mathrm{~K}_{32}, \mathrm{~K}_{33}, \mathrm{~K}_{34}, \mathrm{~K}_{35}, \\
\mathrm{~K}_{36}, \mathrm{~K}_{37}, \mathrm{~K}_{3} 8, \mathrm{~K}_{39}, \mathrm{~K}_{40}, \mathrm{~K}_{41}\end{array}$ \\
\hline & & Nominal & 3 & $\mathrm{~K} 11, \mathrm{~K} 12, \mathrm{~K} 27$ \\
\hline & & İşlevsel & 2 & $\mathrm{~K}_{7}, \mathrm{~K}_{35}$ \\
\hline & \multirow{3}{*}{$\begin{array}{l}\text { Sözel } \\
\text { Gösterge } \\
\text { Farkındalığı }\end{array}$} & Habersiz & 39 & $\begin{array}{l}\text { K1, K2, K3, K4, K5, K6, K8, K9, K10, K1, K12, K13, } \\
\text { K14, K15, K16, K17, K18, K19, K20, K21, K22, K23, } \\
\text { K24, K25, K26, K27, K28, K29, K30, K31, K32, } \\
\mathrm{K}_{33}, \mathrm{~K}_{34}, \mathrm{~K}_{3} 6, \mathrm{~K}_{37}, \mathrm{~K}_{3} 8, \mathrm{~K}_{39}, \mathrm{~K} 40, \mathrm{~K}_{41}\end{array}$ \\
\hline & & Nominal & o & \\
\hline & & İşlevsel & 2 & $\mathrm{~K}_{7}, \mathrm{~K} 35$ \\
\hline
\end{tabular}

Tablo 2'deki verilere göre katılımcıların büyük bir kısmı meddahlık geleneği ile ilgili görüntüsel göstergelerden $(n=36)$ ve sözel göstergelerden ( $n=39)$ habersizdir. Aynı şekilde, bu geleneğin adını karşılayan görüntüsel ve sözel gösterge hakkında işlevsel düzeyde bilgi sahibi olan katılımcı sayısı da çok azdır (n=2). Meddahlık ile ilgili görselleri "hikâyeci, Behlül” (K11), "Osmanh veya Türk medeniyeti” (K12), "eski ecdat oyunu” (K27) gibi ifadelerle Türk geleneği ile ilişkilendiren (nominal düzey) katılımcıların kültürel ögeden büsbütün habersiz olmadıkları anlaşılmaktadır. Kelimenin Arapça olması ve katılımcıların çoğunun Arapça bilmesi, meddahlık kelimesinin birtakım tahminlerle anlamlandırılmasına imkân vermiştir. Birkaç kişi tarafından kavrama; "övünmek" (K4), "takdir etmek" (K10), "bencilik, çok övünme" (K33), "müdahale, devletin başka bir devleti işgal etmesi, sömürge" (K39) gibi literal düzey anlamlar yüklenmiş, diğerleri kültürel ögeyle ilgili bilgi sahibi olmadıklarını ifade etmişlerdir. İşlevsel düzeyde farkındalık sahibi olan katılımcılar (n=2) meddahlığı "komik hikâyeler anlatan kişi” (K7), "eskiden taklit yapan insanlar" (K35) olarak tanımlamışlardır. 


\section{2. İkinci alt probleme ilişkin bulgular ve yorum}

Uluslararası öğrencilerin Mevlevi Sema Törenleri’ne yönelik farkındalıkları Tablo 3’te yer almaktadır.

Tablo 3. Katılımcıların Mevlevi Sema Törenleri’ne Yönelik Farkındalıkları

\begin{tabular}{|c|c|c|c|c|}
\hline Kültürrel Öge & $\begin{array}{l}\text { Farkındalık } \\
\text { Türü }\end{array}$ & $\begin{array}{l}\text { Farkındalık } \\
\text { Düzeyi }\end{array}$ & $\mathbf{n}$ & Katılımcilar \\
\hline \multirow{6}{*}{$\begin{array}{l}\text { Mevlevi } \\
\text { Sema } \\
\text { Törenleri }\end{array}$} & \multirow{3}{*}{$\begin{array}{l}\text { Görüntüsel } \\
\text { Gösterge } \\
\text { Farkındalı̆̆l }\end{array}$} & Habersiz & 8 & K17, K19, K22, K26, K28, K31, K34, K37 \\
\hline & & Nominal & 3 & $\mathrm{~K} 8, \mathrm{~K} 15, \mathrm{~K} 20$ \\
\hline & & İşlevsel & 30 & $\begin{array}{l}\text { K1, K2, K3, K4, K5, K6, K7, K9, K10, K11, K12, K13, } \\
\text { K14, K16, K18, K21, K23, K24, K25, K27, K29, } \\
\mathrm{K}_{30}, \mathrm{~K}_{32}, \mathrm{~K}_{33}, \mathrm{~K}_{35}, \mathrm{~K}_{3} 6, \mathrm{~K}_{3} 8, \mathrm{~K}_{39}, \mathrm{~K} 40, \mathrm{~K} 41\end{array}$ \\
\hline & \multirow{3}{*}{$\begin{array}{l}\text { Sözel } \\
\text { Gösterge } \\
\text { Farkındalığı }\end{array}$} & Habersiz & 18 & $\begin{array}{l}\mathrm{K}_{3}, \mathrm{~K} 8, \mathrm{~K} 14, \mathrm{~K}_{15}, \mathrm{~K} 16, \mathrm{~K}_{17}, \mathrm{~K}_{19}, \mathrm{~K}_{22}, \mathrm{~K}_{23}, \mathrm{~K} 24, \\
\text { K26, K28, К31, K32, К34, К36, К37, К39 }\end{array}$ \\
\hline & & Nominal & 13 & $\begin{array}{l}\text { K1, K4, K6, K10, K12, K13, K18, K20, K27, K29, } \\
\text { K30, K33, K38 }\end{array}$ \\
\hline & & İşlevsel & 10 & $\mathrm{~K}_{2}, \mathrm{~K}_{5}, \mathrm{~K}_{7}, \mathrm{~K} 9, \mathrm{~K} 11, \mathrm{~K} 21, \mathrm{~K}_{25}, \mathrm{~K}_{35}, \mathrm{~K}_{40}, \mathrm{~K}_{41}$ \\
\hline
\end{tabular}

Tablo 3’te katılımcıların "Mevlevi Sema Törenleri”ne ait görsellere aşinalık düzeyi genel olarak yüksek çıkmıştır $(n=30)$. Kültürel ögeyle ilgili görsel aşinalık veya bilgi aynı düzeyde sözel göstergeye yansımamıştır $(\mathrm{n}=10)$. Katılımcıların görsel olarak bildikleri kültürel ögeyi tanımlama ya da açıklamada zorluklar yaşadıkları gözlenmiştir. Sözel göstergeye kıyasla, görüntüsel göstergelerin çağrıştırma ve anlamlandırma gücünün daha fazla olduğu kabul edilmektedir. Çünkü görseller, göstergelerin görüntülü şekilleridir ve belleğe kaydetme ile bellekten çağırma süreçlerinde kolaylaştırıcı işlevler görürler. Mevlevi sema törenlerine ilişkin görseller "Konya'daki meşhur Mevlana" (K2), "dönenler, sema" (K5), "Mevlana, Mevlevi" (K7, K21, K25), "İlahiyata ait, İslami" (K20), "Celaleddin ve ney" (K35) "Celalledinî Belhî diyorlar. Biz Afganistan'da Celalledin Afganî diyoruz. Bu bir çeşit zikirdir.” (K41) gibi doğru tanımlayıcılarla ifade edilirken, kültürel ögenin sözel göstergesi daha çok din kavramıyla ilişkilendirilerek açıklanmıştır. Katılımcıların farkındalık düzeyini gösteren bazı ifadeler şöyledir:

Görüntüsel Gösterge: “Dans yapanlar, Şam’da çok var.”(K8)

Görüntüsel Gösterge: "Dini bir şey, dini dans” (K15)

Görüntüsel Gösterge: "Mahmut Efendi dansı” (K17)

Sözel Gösterge: "Bu bir din.” (K13)

Sözel Gösterge: “Dini oyun. Sufiler oynuyor.”(K29)

Sözel Gösterge: "Mevlid” (K30)

Sözel Gösterge: "Müslüman medeniyeti” (K38)

RumeliDE Dil ve Edebiyat Araştırmaları Dergisi Osmanağa Mahallesi, Mürver Ciçeği Sokak, No:14/8 Kadıköy - ISTANBUL / TÜRKIYE 34714 e-posta: editor@rumelide.com tel: +90 $5057958124,+902167730616$
Address

RumeliDE Journal of Language and Literature Studies Osmanağa Mahallesi, Mürver Çiçeği Sokak, No:14/8

Kadıköy - ISTANBUL / TURKEY 34714

e-mail: editor@rumelide.com,

phone: +90 505 7958124, +90 2167730616 


\section{3. Üçüncü alt probleme ilişkin bulgular ve yorum}

Uluslararası öğrencilerin Âşıklık Geleneği’ne yönelik farkındalıkları Tablo 4’te sunulmaktadır.

Tablo 4. Katılımcıların Âşıklık Geleneği'ne Yönelik Farkındalıkları

\begin{tabular}{|c|c|c|c|c|}
\hline Kültürel Öge & $\begin{array}{l}\text { Farkındalık } \\
\text { Türü }\end{array}$ & $\begin{array}{l}\text { Farkındalık } \\
\text { Düzeyi }\end{array}$ & $\mathbf{n}$ & Katılımcılar \\
\hline \multirow{6}{*}{$\begin{array}{l}\text { Âşıklık } \\
\text { Geleneği }\end{array}$} & \multirow{3}{*}{$\begin{array}{l}\text { Görüntüsel } \\
\text { Gösterge } \\
\text { Farkındalığı }\end{array}$} & Habersiz & 12 & $\begin{array}{l}\text { K9, K11, K14, K16, K19, K23, K24, K26, K32, K37, } \\
\text { K38, K41 }\end{array}$ \\
\hline & & Nominal & 28 & 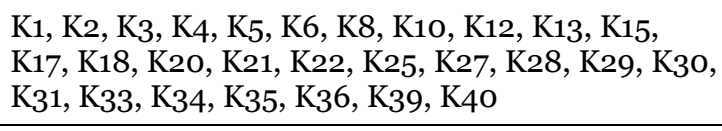 \\
\hline & & İşlevsel & 1 & $\mathrm{~K}_{7}$ \\
\hline & \multirow{3}{*}{$\begin{array}{l}\text { Sözel } \\
\text { Gösterge } \\
\text { Farkındalığı }\end{array}$} & Habersiz & 38 & $\begin{array}{l}\text { K1, K2, K3, K4, K5, K6, K8, K9, K10, K11, K12, K13, } \\
\mathrm{K}_{14}, \mathrm{~K}_{15}, \mathrm{~K} 16, \mathrm{~K} 17, \mathrm{~K} 18, \mathrm{~K} 19, \mathrm{~K} 2 \mathrm{O}, \mathrm{K} 21, \mathrm{~K} 22, \mathrm{~K} 23, \\
\mathrm{~K}_{24}, \mathrm{~K} 25, \mathrm{~K} 26, \mathrm{~K} 28, \mathrm{~K} 29, \mathrm{~K} 30, \mathrm{~K}_{31}, \mathrm{~K}_{32}, \mathrm{~K}_{33}, \\
\mathrm{~K}_{34}, \mathrm{~K}_{3} 6, \mathrm{~K}_{37}, \mathrm{~K}_{3} 8, \mathrm{~K}_{39}, \mathrm{~K} 40, \mathrm{~K}_{41}\end{array}$ \\
\hline & & Nominal & 2 & K27, K35, \\
\hline & & İşlevsel & 1 & $\mathrm{~K}_{7}$ \\
\hline
\end{tabular}

Âşıklık Geleneği’ne ilişkin görseller, Tablo 4'te yer alan katılımcılar tarafından eğlence meclisi gibi algılanmış, âşıklık geleneği içinde önemli bir yeri olan sözden ve içerikten ziyade ezgiye vurgu yapılmıştır (n=28). Görseller; "müzik" (K1), "Türk adetleri, müzik gibi” (K6), "Türk müziği” "(K10), "kanun" (K13), "şarkı" (K21), "şarkı ve şïr söylemek" (K25), "saz” (K33), "müzik aletleri” (K39) olarak algılanmıştır. Kültürel ögenin zengin içeriğini oluşturan şiir ve hikâyeler, beşeri ve İlahi aşklar, kahramanlıklar, toplumsal olaylar hakkında katılımcıların bilgi sahibi olmadıkları, Anadolu insanının hayat ve tabiat tasavvurunu, estetik ve ahlak anlayışını yansıtan "âşıklık" kavramını büyük oranda duymadıkları anlaşılmıştır ( $\mathrm{n=38)}$. Bu kavram (sözel gösterge) katılımcılar tarafından yüzeysel anlamda "sevgili olmak" (K11), "birine âş̧ı olmak" (K17), "birini sevmek" (K19), "sevgi" (K28) olarak açıklanmıştır. Yalnızca bir katılımcı (K7) kültürel ögenin görüntüsel göstergesini "âşıklar türkü söylüyor.”; sözel göstergesini "eskiden âşıklar halk türkülerini sazıyla söylerdi." şeklinde işlevsel düzeyde anlamlandırmıştır.

\subsection{Dördüncü alt probleme ilişkin bulgular ve yorum}

Uluslararası öğrencilerin Karagöz Geleneği’ne yönelik farkındalıkları Tablo 5’te gösterilmektedir.

Tablo 5. Katılımcıların Karagöz Geleneği’ne Yönelik Farkındalıkları

\begin{tabular}{|c|c|c|c|c|}
\hline Kültürel Öge & $\begin{array}{l}\text { Farkindalık } \\
\text { Türü }\end{array}$ & $\begin{array}{l}\text { Farkındalık } \\
\text { Düzeyi }\end{array}$ & $\mathbf{n}$ & Katılımcilar \\
\hline \multirow{4}{*}{ Karagöz } & \multirow{3}{*}{$\begin{array}{l}\text { Görüntüsel } \\
\text { Gösterge } \\
\text { Farkındalı̆̆ı }\end{array}$} & Habersiz & 11 & K1, K3, K8, K9, K20, K21, K22, K28, K31, K39, K41 \\
\hline & & Nominal & 4 & K10, K19, K23, K30 \\
\hline & & İşlevsel & 26 & 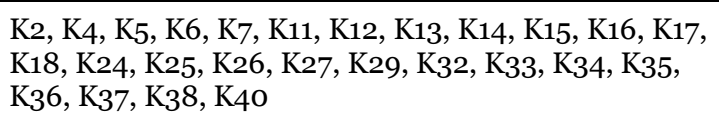 \\
\hline & $\begin{array}{l}\text { Sözel } \\
\text { Gösterge }\end{array}$ & Habersiz & 24 & $\begin{array}{l}\mathrm{K}_{1}, \mathrm{~K}_{3}, \mathrm{~K} 8, \mathrm{~K} 9, \mathrm{~K} 10, \mathrm{~K}_{13}, \mathrm{~K}_{14}, \mathrm{~K} 16, \mathrm{~K}_{17}, \mathrm{~K} 18, \mathrm{~K}_{19}, \\
\mathrm{~K} 2 \mathrm{O}, \mathrm{K} 21, \mathrm{~K} 22, \mathrm{~K} 26, \mathrm{~K} 27, \mathrm{~K} 28, \mathrm{~K} 29, \mathrm{~K}_{30}, \mathrm{~K}_{31}, \mathrm{~K}_{34}, \\
\mathrm{~K}_{3} 8, \mathrm{~K}_{39}, \mathrm{~K} 41\end{array}$ \\
\hline & $\begin{array}{r}\text { eliDE Dil ve Edebi } \\
\text { gğa Mahallesi, Mür } \\
\text { Kadıköy - İST } \\
\text { e-pos } \\
\text { tel: }+9050579\end{array}$ & $\begin{array}{r}\text { Adres } \\
\text { Araşttrmaları Dergisi } \\
\text { Çiçeği Sokak, No:14/8 } \\
\text { UUL / TÜRKIYY 34714 } \\
\text { editor@rumelide.com } \\
\text { 24, +90 216773 0 616 }\end{array}$ & & $\begin{array}{l}\text { ss } \\
\text { iDE Journal of Language and Literature Studies } \\
\text { lağa Mahallesi, Mürver Çiçeği Sokak, No:14/8 } \\
\text { jy - ISTANBUL / TURKEY } 34714 \\
\text { l: editor@rumelide.com, } \\
\text { e: +90 505 7958124, +90 } 216773 \text { o } 616\end{array}$ \\
\hline
\end{tabular}




\begin{tabular}{lll}
\hline Nominal & 7 & $\mathrm{~K} 2, \mathrm{~K}_{15}, \mathrm{~K}_{23}, \mathrm{~K} 24, \mathrm{~K} 25, \mathrm{~K}_{32}, \mathrm{~K}_{33}$ \\
\hline İşlevsel & 10 & $\mathrm{~K} 4, \mathrm{~K} 5, \mathrm{~K} 6, \mathrm{~K} 7, \mathrm{~K} 11, \mathrm{~K} 12, \mathrm{~K}_{35}, \mathrm{~K}_{36}, \mathrm{~K}_{37}, \mathrm{~K}_{40}$ \\
\hline
\end{tabular}

Tablo 5’teki verilere göre, kelime oyunlarına, karşılıklı atışmaya ve yanlış anlamaya dayalı olan "Karagöz"e ait görseller katılımcıların yarısından fazlası tarafından doğru algılanmıştır $(n=26)$. Görüntüsel göstergenin doğru anlamlandırılması, katılımcıların Türkçe öğrenme süreçlerinde Türk kültür yapısını tanımalarına değil, kültürel ögenin küçük telaffuz farklılıklarıyla geniş bir coğrafyada yaşıyor olmasına dayanmaktadır. Suriyeliler "Karagoz ve Ayvaz" (K7), Endonezyalılar "Wayang" (K15), Mısırlılar "Karkoz" (K33), Faslılar "Karakiz" (K37) adıyla benzer gölge oyunlarının bir kültür ögesi olarak ülkelerinde yaşadığını beyan etmişlerdir. Kültürel unsuru doğru biçimde anlamlandıran katılımclar genel olarak "kukla" kelimesi etrafında tanımlama yapmışlardır. Katılımcılar arasında Karagöz’ün sözel gösterge olarak bilinirliği görüntüsel gösterge bilinirliğine oranla çok daha düşüktür $(n=10)$. Çünkü görüntüsel göstergeler sözel göstergelere göre daha kolay algılanabilmektedir. Sözel göstergeye yüklenen bazı anlamlar şu şekildedir:

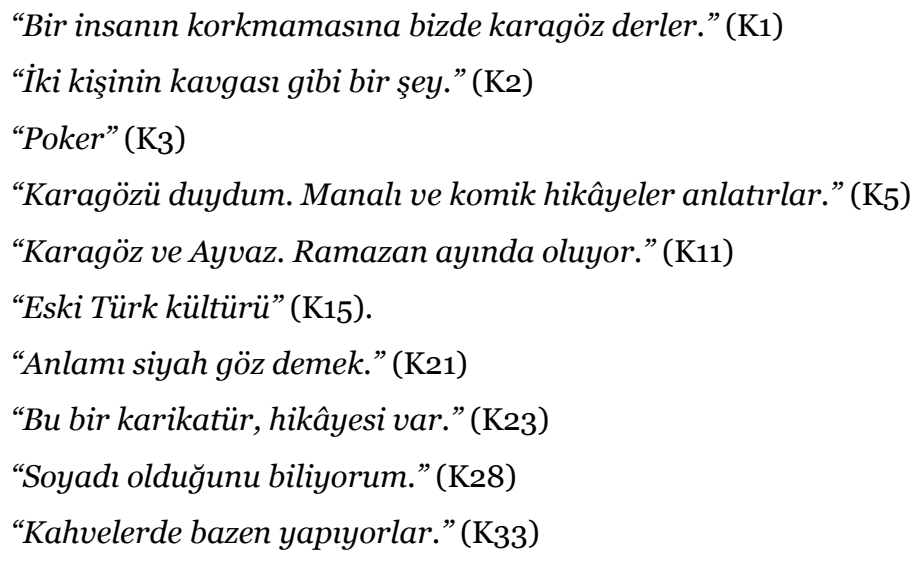

\subsection{Beşinci alt probleme ilişkin bulgular ve yorum}

Uluslararası öğrencilerin Geleneksel Sohbet Toplantıları'na yönelik farkındalıkları Tablo 6'da yer almaktadır.

Tablo 6. Katılımcıların Geleneksel Sohbet Toplantıları’na Yönelik Farkındalıkları

\begin{tabular}{|c|c|c|c|c|}
\hline Kültürel Öge & $\begin{array}{l}\text { Farkındalık } \\
\text { Türüi }\end{array}$ & $\begin{array}{l}\text { Farkındalık } \\
\text { Düzeyi }\end{array}$ & $\mathbf{n}$ & Katılımcılar \\
\hline \multirow{6}{*}{$\begin{array}{l}\text { Geleneksel } \\
\text { Sohbet } \\
\text { Toplantıları }\end{array}$} & \multirow{3}{*}{$\begin{array}{l}\text { Görüntüsel } \\
\text { Gösterge } \\
\text { Farkındalığg }\end{array}$} & Habersiz & 15 & $\begin{array}{l}\text { K1, K8, K10, K17, K19, K22, K23, K24, K26, K30, K31, } \\
\mathrm{K}_{34}, \mathrm{~K}_{3} 6, \mathrm{~K}_{39}, \mathrm{~K}_{41}\end{array}$ \\
\hline & & Nominal & 24 & $\begin{array}{l}\mathrm{K}_{2}, \mathrm{~K}_{3}, \mathrm{~K} 4, \mathrm{~K} 6, \mathrm{~K} 5, \mathrm{~K} 9, \mathrm{~K} 11, \mathrm{~K} 12, \mathrm{~K}_{13}, \mathrm{~K}_{14}, \mathrm{~K}_{15}, \mathrm{~K} 16, \\
\mathrm{~K} 18, \mathrm{~K} 20, \mathrm{~K} 21, \mathrm{~K} 25, \mathrm{~K} 28, \mathrm{~K}_{29}, \mathrm{~K}_{32}, \mathrm{~K}_{33}, \mathrm{~K}_{27}, \mathrm{~K}_{37}, \\
\mathrm{~K}_{3} 8, \mathrm{~K} 4 \mathrm{O}\end{array}$ \\
\hline & & İşlevsel & 2 & $\mathrm{~K}_{7}, \mathrm{~K} 35$ \\
\hline & \multirow{3}{*}{$\begin{array}{l}\text { Sözel } \\
\text { Gösterge } \\
\text { Farkındalığı }\end{array}$} & Habersiz & 11 & K6, K13, K17, K19, K21, K24, K26, K34, K37, K38, K41 \\
\hline & & Nominal & 26 & $\begin{array}{l}\mathrm{K} 1, \mathrm{~K} 2, \mathrm{~K}_{3}, \mathrm{~K} 4, \mathrm{~K} 8, \mathrm{~K} 9, \mathrm{~K} 10, \mathrm{~K} 11, \mathrm{~K} 12, \mathrm{~K} 14, \mathrm{~K} 15, \mathrm{~K} 16, \\
\mathrm{~K} 18, \mathrm{~K} 20, \mathrm{~K} 22, \mathrm{~K} 23, \mathrm{~K} 25, \mathrm{~K} 27, \mathrm{~K} 28, \mathrm{~K} 29, \mathrm{~K} 30, \mathrm{~K} 31, \\
\mathrm{~K}_{32}, \mathrm{~K}_{33}, \mathrm{~K}_{3} 6, \mathrm{~K}_{39}\end{array}$ \\
\hline & & İşlevsel & 4 & $\mathrm{~K}_{5}, \mathrm{~K}_{7}, \mathrm{~K}_{35}, \mathrm{~K}_{40}$ \\
\hline
\end{tabular}

\begin{tabular}{r|l} 
Adres & $\begin{array}{l}\text { Address } \\
\text { RumeliDE Dil ve Edebiyat Araşturmaları Dergisi }\end{array}$ \\
RumeliDE Journal of Language and Literature Studies \\
Osmanağa Mahallesi, Mürver Çiçeği Sokak, No:14/8 & Osmanağa Mahallesi, Mürver Çiçeği Sokak, No:14/8 \\
Kadıköy - İSTANBUL / TÜRKIYE 34714 & Kadıköy - ISTANBUL / TURKEY 34714 \\
e-posta: editor@rumelide.com & $\begin{array}{l}\text { e-mail: editor@rumelide.com, } \\
\text { phone: +90 505 7958124, +90 } 216773 \text { o } 616\end{array}$ \\
tel: +90 505 7958124, +90 216 773 o 616 &
\end{tabular}


Erkeklerin bir araya geldiği geleneksel sohbet toplantılarında, her bireyin yazılı olmayan kurallar çerçevesinde belli rolleri vardır. Esas amaç sohbet olmakla birlikte, toplantılarda güzel vakit geçirmek de önemlidir. Geleneksel sohbet toplantıları Müslüman toplumların benzer yaşam pratiklerini anımsatmaktadır. Buna rağmen Tablo 6 incelendiğinde katılımcıların, kültürel unsurun görüntüsel göstergelerini işlevsel olarak yeterli düzeyde algılayamadıkları görülmektedir $(n=2)$. Bu durum, kullanılan görsellerin kültürel ögeyi tam olarak yansıtmamasından kaynaklanmış olabilir. Görseller "düğün" (K2), "toplant"” (K6), "çiğ köfte" (K13), "oyun oynama" (K20), "şarkı söyleme" (K27), "hamamdaki gençlerin eğlenmesi” (K41) gibi ifadelerle daha çok nominal düzeyde açıklanmıştır. Kültürel ögenin sözel göstergesi ise katılımcllara daha fazla tanıdık gelmiştir $(n=26)$. Bunun sebebi, sözel göstergenin karşıladığı nesne veya durumu anımsatıcı olmasıdır. Katılımcıların kültürel ögeyle ilgili nominal farkındalıklarının, bir bilgi veya bilinçten kaynaklanmadığı görüşme esnasında gözlenmiştir. Ortaya çıkan sonuç daha çok "sohbet" ve "toplantı" sözcüklerinin görsellerle ilişkilendirilerek yorumlanmasına dayanmaktadır. Bazı katılımcıların işlevsel düzeydeki farkındalıklarını gösteren ifadeler şöyledir:

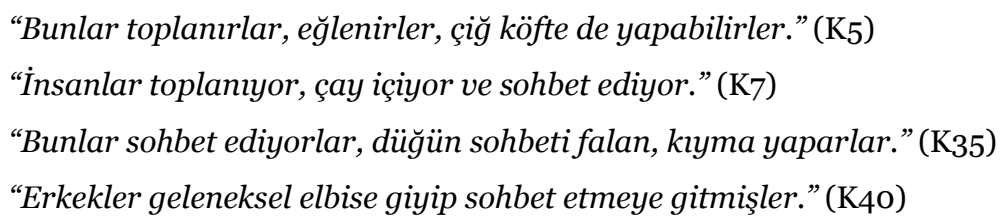

\subsection{Altıncı alt probleme ilişkin bulgular ve yorum}

Uluslararası öğrencilerin Kırkpınar Yağlı Güreş Festivali’ne yönelik farkındalık düzeyi Tablo 7’de yer almaktadır.

Tablo 7. Katılımcıların Kırkpınar Yağlı Güreş Festivali’ne Yönelik Farkındalıkları

\begin{tabular}{|c|c|c|c|c|}
\hline Kültürel Öge & $\begin{array}{l}\text { Farkındalık } \\
\text { Türü }\end{array}$ & $\begin{array}{l}\text { Farkındalık } \\
\text { Düzeyi }\end{array}$ & $\mathbf{n}$ & Katılımcılar \\
\hline \multirow{6}{*}{$\begin{array}{l}\text { Kırkpınar } \\
\text { Yağlı Güreş } \\
\text { Festivali }\end{array}$} & \multirow{3}{*}{$\begin{array}{l}\text { Görüntüsel } \\
\text { Gösterge } \\
\text { Farkındalığı }\end{array}$} & Habersiz & 28 & $\begin{array}{l}\mathrm{K} 1, \mathrm{~K} 2, \mathrm{~K}_{5}, \mathrm{~K} 6, \mathrm{~K} 9, \mathrm{~K} 10, \mathrm{~K}_{13}, \mathrm{~K}_{15}, \mathrm{~K} 17, \mathrm{~K} 18, \mathrm{~K} 19, \\
\mathrm{~K} 2 \mathrm{O}, \mathrm{K} 22, \mathrm{~K} 23, \mathrm{~K} 24, \mathrm{~K} 25, \mathrm{~K} 26, \mathrm{~K} 27, \mathrm{~K} 28, \mathrm{~K} 30, \\
\mathrm{~K}_{31}, \mathrm{~K}_{33}, \mathrm{~K}_{3} 6, \mathrm{~K}_{37}, \mathrm{~K}_{3} 8, \mathrm{~K}_{39}, \mathrm{~K}_{40} \text {, K41 }\end{array}$ \\
\hline & & Nominal & 9 & K4, K8, K11, K12, K16, K21, K29, K32, K34 \\
\hline & & İşlevsel & 4 & $\mathrm{~K}_{3}, \mathrm{~K}_{7}, \mathrm{~K}_{14}, \mathrm{~K}_{35}$ \\
\hline & \multirow{3}{*}{$\begin{array}{l}\text { Sözel } \\
\text { Gösterge } \\
\text { Farkındalığı }\end{array}$} & Habersiz & 35 & $\begin{array}{l}\text { K1, K2, K3, K5, K6, K8, K9, K10, K11, K12, K13, } \\
\text { K15, K17, K18, K19, K20, K22, K23, K24, K25, K26, } \\
\text { K27, K28, K29, K30, K31, K32, K33, K34, K36, } \\
\mathrm{K}_{37}, \mathrm{~K}_{3} 8, \mathrm{~K}_{39}, \mathrm{~K} 40, \mathrm{~K} 41\end{array}$ \\
\hline & & Nominal & 4 & $\mathrm{~K}_{4}, \mathrm{~K} 14, \mathrm{~K} 16, \mathrm{~K} 21$ \\
\hline & & İşlevsel & 2 & K7, K35 \\
\hline
\end{tabular}

Yedi asırlık geleneği olan Kırkpınar Yağlı Güreşleri Türklerin ata sporudur. Pehlivanlık kültürünü yaşatmak amacıyla her yıl festival olarak organize edilen Kırkpınar Yağlı Güreşleri yerel bir etkinlik değildir. Aksine kitle iletişim araçlarıyla tanıtımı yapılan, bilinirliği olan bir spordur. Tablo 7’ye göre, katılımcıların, Kırkpınar Yağlı Güreş Festivali’nin görüntüsel göstergeleri ( $n=28)$ ile sözel göstergesine $(\mathrm{n}=35)$ ilişkin farkındalıkları büyük ölçüde "habersizlik" düzeyindedir. Söz konusu kültürel öge "güreş" (K4, K8, K11, K12, K16, K21, K29, K32, K34), "savaş gibi bir şey" (K9), "Orta Asya'da, Hindistan, Pakistan ve Türkiye’de olan bir yarış" (K14), "geleneksel yağh güreş” (K7), "Sakarya’nın etrafinda

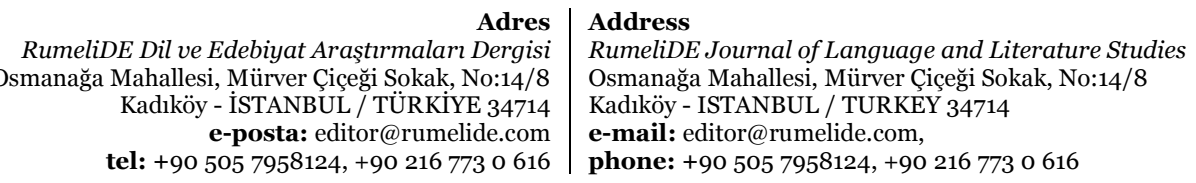


bir şehirde oldu. Yağ sürüp güreşiyorlar.” (K35) gibi cümlelerle ifade edilmiştir. Katılımcılara sunulan görüntüsel ve sözel göstergeler, karşıladığı nesneyi büyük oranda çağrıştırmaktadır. Kültürel ögenin genel olarak habersizlik derecesinde bilinmesi, katılımcıların eşik düzeydeki geleneksel spor bilgisinden yoksun olmasıyla açıklanabilir.

\subsection{Yedinci alt probleme ilişkin bulgular ve yorum}

Uluslararası öğrencilerin Alevî-Bektaşî Ritüeli Semah'a yönelik farkındalıkları Tablo 8'de yer almaktadır.

Tablo 8. Katılımcıların Alevî-Bektaşî Ritüeli Semah’a Yönelik Farkındalıkları

\begin{tabular}{|c|c|c|c|c|}
\hline Kültürel Öge & $\begin{array}{l}\text { Farkındalık } \\
\text { Türüi }\end{array}$ & $\begin{array}{l}\text { Farkındalık } \\
\text { Düzeyi }\end{array}$ & $\mathbf{n}$ & Katılımcılar \\
\hline \multirow{6}{*}{$\begin{array}{l}\text { Alevi-Bektaşi } \\
\text { Ritüeli Semah }\end{array}$} & \multirow{3}{*}{$\begin{array}{l}\text { Görüntüsel } \\
\text { Gösterge } \\
\text { Farkındalı̆̆1 }\end{array}$} & Habersiz & 40 & 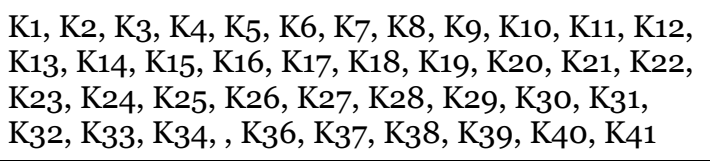 \\
\hline & & Nominal & 1 & K35 \\
\hline & & İşlevsel & o & \\
\hline & \multirow{3}{*}{$\begin{array}{l}\text { Sözel } \\
\text { Gösterge } \\
\text { Farkındalığı }\end{array}$} & Habersiz & 38 & $\begin{array}{l}\text { K1, K2, K4, K5, K6, K8, K9, K10, K11, K12, K13, } \\
\text { K14, K,15, K16, K17, K18, K19, K20, K21, K22, K23, } \\
\text { K24, K25, K26, K27, K28, K29, K30, K31, K32, } \\
\text { K33, K34, K36, K37, K38, K39, K40, K41 }\end{array}$ \\
\hline & & Nominal & 2 & $\mathrm{~K}_{3}, \mathrm{~K}_{7}$ \\
\hline & & İşlevsel & 1 & K35 \\
\hline
\end{tabular}

Tablo 8 incelendiğinde Alevî-Bektaşî ritüeli olarak semahın görüntüsel $(n=0)$ ve sözel gösterge farkındalığının $(n=1)$ işlevsel düzeyde oluşmadığı söylenebilir. Katılımcıların sözü edilen kültürel ögenin görüntüsel göstergelerini $(n=40)$ ve sözel göstergelerini $(n=38)$ anlama ve yorumlama bilgisine sahip olmadıkları tablodan anlaşılmaktadır. Bu nedenle görseller ve sözel gösterge belli ritüeller eşliğinde icra edilen bir inanma biçiminden ziyade, genellikle "düğün" (K1), "oyun" (K13), "Türk düğünü" (K14), "milli oyun" (K23), "kutlama" (K25), "halay çekme" (K39), "dans etme" (K40, K41) gibi eğlenmeyle ilişkili kavramlarla karşılanmıştır. Katılımcıların büyük çoğunluğu kültürel unsurla ilgili hiçbir bilgi sahibi olmadıklarını belirtmişlerdir. Nominal düzeydeki sözel gösterge farkındalığı "Alevî" ve "Bektaşî" sözcükleriyle anlamsal bağ kurulmak suretiyle izah edilmiştir: "Alevilerin semah dansı var. Ne olduğunu bilmiyorum." (K3) ile "Alevî, Bektaşi duydum.” (K7) ifadeleri kültürel ögeye yönelik düşük düzeyli bir aşinalığın varlığına işaret etmektedir. Alevî-Bektaşi ritüeli hakkında işlevsel düzeyde farkındalık sahibi olduğu değerlendirilen katılımcı (K35) kültürel ögeyi "Alevilerin ibadet şekli" olarak tanımlamıştır.

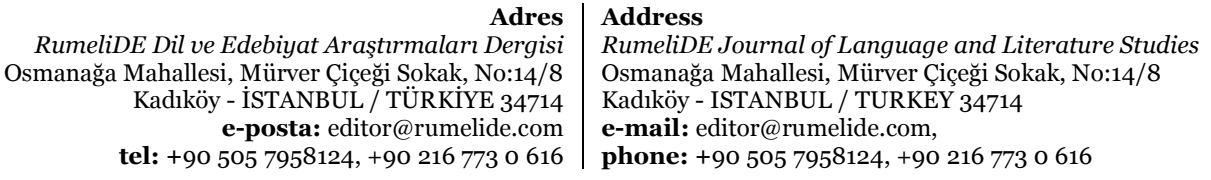




\subsection{Sekizinci alt probleme ilişkin bulgular ve yorum}

Uluslararası öğrencilerin Mesir Macunu Festivali’ne yönelik farkındalıkları Tablo g'da yer almaktadır.

Tablo 9. Katılımcıların Mesir Macunu Festivali’ne Yönelik Farkındalıkları

\begin{tabular}{|c|c|c|c|c|}
\hline Kültürel Öge & $\begin{array}{l}\text { Farkındalık } \\
\text { Türü }\end{array}$ & $\begin{array}{l}\text { Farkındalık } \\
\text { Düzeyi }\end{array}$ & $\mathbf{n}$ & Katılımcılar \\
\hline \multirow{6}{*}{$\begin{array}{l}\text { Mesir } \\
\text { Macunu } \\
\text { Festivali }\end{array}$} & \multirow{3}{*}{$\begin{array}{l}\text { Görüntüsel } \\
\text { Gösterge } \\
\text { Farkındalığı }\end{array}$} & Habersiz & 40 & $\begin{array}{l}\text { K1, K2, K3, K4, K5, K6, K7, K8, K9, K10, K11, K12, } \\
\text { K13, K14, K15, K16, K17, K18, K19, K20, K21, K22, } \\
\text { K23, K24, K25, K26, K27, K28, , K30, K31, K32, } \\
\mathrm{K}_{33}, \mathrm{~K}_{34}, \mathrm{~K}_{35}, \mathrm{~K}_{3} 6, \mathrm{~K}_{37}, \mathrm{~K}_{3} 8, \mathrm{~K}_{39}, \mathrm{~K} 40, \mathrm{~K}_{41}\end{array}$ \\
\hline & & Nominal & 1 & K29 \\
\hline & & İşlevsel & o & \\
\hline & \multirow{3}{*}{$\begin{array}{l}\text { Sözel } \\
\text { Gösterge } \\
\text { Farkındalığı }\end{array}$} & Habersiz & 41 & 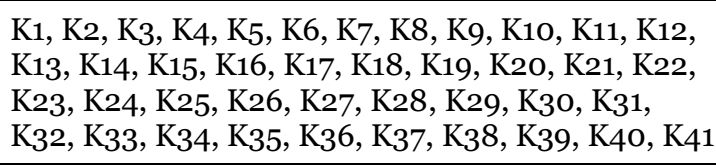 \\
\hline & & Nominal & o & \\
\hline & & İşlevsel & o & \\
\hline
\end{tabular}

Tablo 9'a göre katılımcıların Mesir Macunu Festivali’ne ilişkin görüntüsel gösterge farkındalıkları $(n=40)$ ile sözel gösterge farkındalıkları $(n=41)$ habersizlik düzeyindedir. Katılımcılar Mesir Macunu Festivali'ni hiç duymadıklarını ifade etmişlerdir. Kullanılan görsellerin bazıları katılımcılar tarafından "millete kalem veriyorlar." (K17) şeklinde yorumlanmıştır. Yaşadıkları kentlerde muhtemelen gördükleri birtakım organizasyonların tesiriyle, kültürel ögeyi yansıtan görselleri "mum veya Konya'da abur cubur gibi çocuklara verilen bir şey"e (K29) benzetenler olmuştur. Görselleri "havai fişek" (K3, K11) olarak ifade edenler, büyük olasıllıkla küçük ve renkli ambalajlı çubuklar şeklinde görülen nesneyi zihinsel olarak renklerle ilişkilendirme eğilimi göstermişlerdir.

\section{Tartışma ve sonuç}

Geride bıraktığımız yüzyılın başında ve ortalarında yaşanan iki dünya savaşı, başta insan hayatı olmak üzere, insanlığın biriktirdiği her türden mirasa büyük zarar vermiştir. Savaş ve istikrarsızlıkların tahrip edici sonuçlarını tecrübe eden dünya, ulusal kimliğin korunmasında kültürün önemini fark edince uluslararası boyutta örgütlenme yoluna gitmiştir. Ne var ki yüzyılın sonlarına doğru sosyal, ekonomik ve kültürel alanlarında yaşanan hızlı değişim küreselleşme olarak adlandırılan yeni bir dünya düzenini beraberinde getirmiştir (Kolaç, 2009: 19). Yüzyılın ilk yarısında, savaşların etkisiyle kültürel mirasın maddi veya somut alanlarında görülen tahribat, yüzyılın sonlarında ortaya çıkan yeni eğilimler yüzünden daha çok kültürün maddi/somut olmayan unsurlarına yönelmiştir. Bunun da etkisiyle, insanlığın ortak hafızası olarak nitelenen kültürel mirasın yok olmasına yönelik öteden beri var olan entelektüel talep UNESCO tarafından haklı bulunmuş, SOKÜM uluslararası düzeydeki sözleşmelerle resmî belge niteliği kazanmıştır. Böylece folkloru korumanın ulusal kimliği ve kültürü korumak anlamına geldiği düşüncesi UNESCO tarafından kabul edilmiştir (Öcal, 2009: 8).

Kültürel mirası, birtakım yasal enstrümanlara dayanan kamu otoritesiyle korumak ve yaşatmak yeterli olmayabilir. Bunun için kültürel mirası hayatla irtibatlı kılacak, onu sonraki nesillere aktaracak ve belki de günümüzün geçişken dünyasında bir milli kimlik göstergesi olarak uluslararası alanda

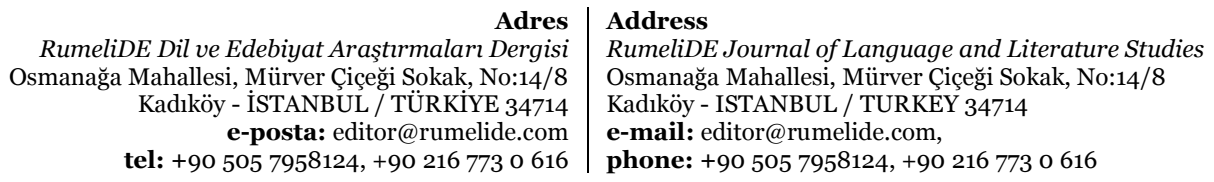


bilinirliğini artıracak davranış kodlarına ihtiyaç vardır. Türkçenin yabancı dil olarak öğretimi bu alanda kullanılabilecek uygun bir araç gibi görünmektedir. Türkiye, hâlihazırda en fazla uluslararası öğrenci çeken ilk 10 ülke arasında yer almaktadır (YÖK, 2020). Son yllarda Türkçeye duyulan ilgi, SOKÜM başta olmak üzere, kültürel mirasımızın bilinirliği için önemli fırsatlar sunmaktadır. Küresel dünyanın Batı merkezli, hibrit ve dayatmacı egemenliğine (İçli, 2001: 166) karşı Türk kültürünün tarihsel olarak sahip olduğu perspektifi Türkçe öğretimi aracılığıyla alternatif bir değer olarak sunmak mümkündür. Bu anlayıştan hareketle yapılan bu çalışmada somut olmayan kültürel değerlerimizin dil öğretim süreçlerine yeterli düzeyde aktarılmadığı tespit edilmiştir. SOKÜM listesinde yer alan kültürel ögelerle ilgili çalışma kapsamında elde edilen sonuçlar, görüntüsel göstergelere yönelik farkındalık düzeyi ile sözel göstergelere yönelik farkındalık düzeyi olarak iki kategoride ele alınmıştır:

Çalışma grubunu oluşturan katılımcıların yaklaşık \%88’i Meddahlığı, \%20'si Mevlevi Sema Törenleri'ni, \%29'u Âşıklık Geleneği’ni, \%27'si Karagöz'ü, \%37'si Geleneksel Sohbet Toplantıları'nı, \%68’i Kırkpınar Yağlı Güreş Festivali’ni, \%98’i Alevî-Bektaşî Ritüeli Semah’ı ve \%98’i Mesir Macunu Festivali’ni görüntüsel gösterge olarak açıllayamamışlardır. Bu sonuca göre katılımcılar; meddahlık, Kırkpınar Yağlı Güreş Festivali, Alevî-Bektaşî Ritüeli Semah ve Mesir Macunu Festivali'nden büyük ölçüde habersizdir. Mevlevi Sema Törenleri, Âşıklık Geleneği, Karagöz ile Geleneksel Sohbet Toplantıları'nın bilinirliği katılımcılar arasında nispeten daha yüksektir.

Kültürel ögelerin farkındalık düzeylerinin düşük ya da yüksekliğinin, görüntüsel göstergelerin karşıladığı nesne ya da kavramı yansıtma başarısıyla ilişkili olduğu çalışma sürecinde gözlenmiştir. Örneğin Âşıklık Geleneği ile ilgili görseller, kolaylıkla müzikle ilişkilendirilebilecek tarzdadır. Bu nedenle katılımcıların yalnızca \%29'u Âşıklık Geleneği'nin görüntüsel göstergesini tanımlayamamıştır. Buna karşılık kültürel ögenin sözel göstergesine yönelik habersizlik düzeyi \%93’tür. Bu fark görüntüsel ve sözel göstergelerin gördüğü işlevle de ilgilidir. Görseller bilgi sahibi olmadan da yorum yapabilme imkânı sağlarken, sözel göstergeler nesnenin kendisi hakkında bilgi sahibi olmayı gerektirmektedir.

Çalışma kapsamında ele alınan kültürel unsurların sözel göstergelerine yönelik farkındalık düzeyi genel olarak daha düşüktür. Katılımcıların \%95’i Meddahlık Geleneği’ne, \%44’ü Mevlevi Sema Törenleri'ne, \%93'ü Âşıklık Geleneği’ne, \%59'u Karagöz'e, \%27'si Geleneksel Sohbet Toplantıları'na, \%85’i Kırkpınar Yağlı Güreş Festivali’ne, \%93’ü Alevî-Bektaşî Ritüeli Semah’a ve \%10o’ü Mesir Macunu Festivali’ne sözel gösterge olarak tamamen yabancıdır. Mevlevi Sema Törenleri, Karagöz ve Geleneksel Sohbet Toplantıları ile ilgili nispeten düşük düzeyli habersizlik, diğer kültür ögelerinde oldukça yüksektir. Bu sonuca göre ileri düzey Türkçe bildiği varsayılan uluslararası öğrencilerin, SOKÜM'e yönelik farkındalıkları düşüktür. Mesir Macunu Festivali ise katılımcılar tarafından kavramsal olarak hiç bilinmemektedir.

SOKÜM listesinde yer alan ve çalışma kapsamına alınan kültürel unsurların tamamının görüntüsel göstergelerini işlevsel düzeyde anlayıp yorumlayabilen katılımcı oranı yaklaşık \%8 civarında iken, sözel göstergeleri işlevsel düzeyde anlayıp yorumlayan katılımcı oranı yaklaşı \%4’tür. Bu oranlar, çalışmaya dâhil edilen kültürel ögelerin görüntüsel ve sözel gösterge ortalamalarıdır. Bu sonuçlar; Diller İçin Avrupa Ortak Başvuru Metni’ndeki tanımlayıcılara göre ileri düzey Türkçe bilen ve en az iki yıldır Türkiye'de yaşayan uluslararası öğrencilerin SOKÜM listesinde ayırt edici olduğu değerlendirilen kültürel ögeleri yeterli düzeyde bilmediklerini göstermektedir.

Temsil ettiği toplumun zihinsel kodlarını, duygu dünyasını, hayat ve tabiat algısını açlk veya örtük biçimde aktarımını da içeren dil öğretimi, bu yönüyle toplumlar arasında güçlü bağların oluşmasını

\begin{tabular}{r|l} 
Adres & Address \\
RumeliDE Dil ve Edebiyat Araşttrmalar Dergisi & RumeliDE Journal of Language and Literature Studies \\
Osmanağa Mahallesi, Mürver Çiçeği Sokak, No:14/8 & Osmanağa Mahallesi, Mürver Çiçeği Sokak, No:14/8 \\
Kadıköy - İSTANBUL / TÜRKIYE 34714 & Kadıköy - ISTANBUL / TURKEY 34714 \\
e-posta: editor@rumelide.com & e-mail: editor@rumelide.com, \\
phone: +90 505 7958124, +90 2167730616
\end{tabular}


sağlayan önemli bir araçtır. Dil aynı zamanda toplumların saygınlığını, nüfuzunu, kimliğini (Wodak, 2012: 229) yansıtan ve onu değerli kılan bir güç göstergesidir (Fairclough, 1989). Kültür de geleneksel tanımlamaların ötesinde, uluslararası misyonu olan, toplumlar arasında etkileşim kuran (Purtaş, 2013: 2) ve diplomatik misyonlar üstlenen yumuşak güç (Nye: 1990: 168) olarak algılanmaktadır. Bir egemenlik göstergesi olarak dilin ve diplomatik bir araç olarak kültürün toplumsal ve siyasal olarak yeniden tanımlandıkları biçimleriyle Türkçe öğretiminde yeterli düzeyde yer alması gerektiği değerlendirilmektedir. Bu kapsamda;

1. Yabancılara Türkçe öğretmek amacıyla hazırlanan ders kitaplarında SOKÜM'e yeterince yer verilebilir.

2. Ders içi ve ders dışında, temel dil becerileri ile ilgili etkinlikler SOKÜM’le ilişkilendirilebilir.

3. İmkân olması halinde, "kültür arkadaşlığı" gibi uygulamalarla SOKÜM listesinde yer alan kültürel unsurlar birer dil öğretim aracı olarak kullanabilir.

4. Türkçeyi yabancı dil olarak öğretenler, öğrencileri sınıf dışı özerk öğrenme süreçlerinde kültürel miras konularına yönlendirebilir.

5. Türkçenin yabancı dil olarak öğretiminde "Türk Kültürü" adı altında belli yeterlik standartları oluşturulabilir, ölçme ve değerlendirme süreçlerinde bu standartların karşılanması istenebilir.

\section{Kaynakça}

Akarsu, B. (1998), Dil-kültür bağlantısı. İstanbul: İnkılap.

Akcaoğlu, C. (2017). Somut olmayan kültürel miras ve yabancı dil olarak Türkçe öğretiminde kullanımı (Yayımlanmamış Yüksek Lisans Tezi). Hacettepe Üniversitesi Türkiyat Araştırmaları Enstitüsü.

Aksan, D. (1995). Her yönüyle dil. Ankara: TDK.

Altınok, K. (2020). Kültürel miras ve dil öğretimi bağlamında gazi TÖMER yabancllar için Türkçe öğretim seti. Uluslararası Halkbilimi Araştırmaları Dergisi, 3(5), 223-246.

Baltacıŏ̆lu, İ. H. (1964). Ziya Gökalp. Sosyoloji Konferansları, Otuz Üçüncü Konferans, (5), İstanbul.

Bourdieu, P. (1991). Language and symbolic power. Cambridge, Mass: Harvard University Press.

Bruns, G. L. (1984). Language and power. Chicago Review, 34(2), 27-43. https://doi.org/10.2307/25305244

Fairclough, N. (1989). Language and power. London: Longman.

Göçer, A. (2012). Dil-kültür ilişkisi ve etkileşimi üzerine. Türk Dili, (729), 50-57.

Gökalp, Z. (2019). Türkçülüğün esasları. Eskişehir: T.C. Anadolu Üniversitesi.

Günay, V. D. (2008). Görsel okuryazarlık ve imgenin anlamlandırılması. Süleyman Demirel Universitesi Güzel Sanatlar Fakültesi Hakemli Dergisi ART-E 1(1), 1-29.

Güvenç, B. (1994). İnsan ve kültür. İstanbul: Remzi.

Iriye, A. (1979). Culture and power: International relations as intercultural relations. Diplomatic History, 3(2), 115-128. https://www.jstor.org/stable/24909929

İçli, G. (2001). Küreselleşme ve kültür. Cumhuriyet Üniversitesi Sosyal Bilimler Dergisi, 25(2), 163172.

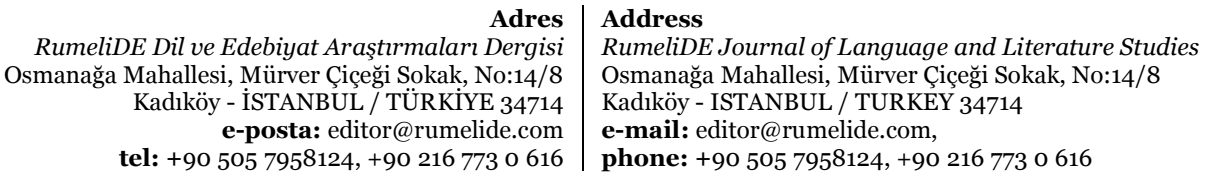

tel: +90 505 7958124, +90 2167730616 
Janks H. (2008). Teaching language and power. In S. May and N. H. Hornberger (Eds.), Encyclopedia of language and education, language policy and political issues in education (2nd ed., Vol. 1: pp. 183-193). Springer Science+Business Media LLC.

Kachru, B. B. (1986). The power and politics of English. World Englishes, 5(2-3), 121-140. https://doi.org/10.1111/j.1467-971X.1986.tboo720.x

Kafesoğlu, İ. (1998), Türk millî kültürü. İstanbul: Ötüken.

Kaplan, M. (1992). Kültür ve dil. İstanbul: Dergâh.

Karakoç Öztürk, B. (2020). Yabancı dil olarak Türkçe öğretiminde somut olmayan kültürel mirasın aktarımı. Çukurova Üniversitesi Türkoloji Araştırmaları Dergisi, 5(2), 288-312. https://doi.org/10.32321/cutad.781673

Karasar, N. (2019). Bilimsel araştırma yöntemi. Ankara: Nobel Yayın Dağıtım.

Kavcar, C. (1987). Türk dili ve edebiyatı öğretimi. Ankara Üniversitesi Eğitim Bilimleri Fakültesi Dergisi, (20)1, 261-273. https://doi.org/10.1501/Egifak_0000001077

Keyman, F. (2001). Globalization and Turkey: Economy, society and culture. (RSC No. 2001/38). EUI Working Paper. European University Institute.

Kolaç, E. (2009). Somut olmayan kültürel mirası koruma, bilinç ve duyarlılık oluşturmada Türkçe eğitiminin önemi. Milli Folklor, 11(82), 19-31.

Kumaravadivelu, B. (2008). Cultural globalization and language education. New Haven: Yale University Press.

Kültür ve Turizm Bakanlığı, (2021). UNESCO somut olmayan kültürel miras listesi. https://aregem.ktb.gov.tr/TR-50838/unesco-somut-olmayan-kulturel-miras-listesi.html

Melanlığlu, D. (2008)._Kültür aktarımı açısından Türkçe öğretim programları. Eğitim ve Bilim, 33(150), 64-73.

Miles, M. B., \& Huberman, A. M. (1994). An expanded sourcebook: Qualitative data analysis. London: SAGE Publications.

Moralı, G. \& Öner, G. (2019). Yabancı dil olarak Türkçe ders kitaplarında somut olmayan kültürel miras unsurlarının incelenmesi. Turkish Studies Language and Literature, 14(3), 1345-1357. http://dx.doi.org/10.29228/TurkishStudies.30167

Nye, Joseph. S. Jr. (1990). Soft power. Foreign Policy, (80), 153-171. https://doi.org/10.2307/1148580

Okur, A. (2013). Millı̂ kültür ve folklorun Türkçe ders kitapları aracılığıyla aktarımı. Adıyaman Üniversitesi Sosyal Bilimler Enstitüsü Dergisi Türkçenin Eğitimi Öğretimi Özel Sayısı 6(11), 877-904. https://doi.org/10.14520/adyusbd.470

Öcal, O. (2009). Somut olmayan kültürel miras ve kültürel ifade çeşitliliği. Milli Folklor, 11(82), 6-12.

Öcal, O. (2013). Terim olarak somut olmayan kültürel miras. Milli Folklor, 12(100), 5-13.

Pill, J., \& Harding, L. (2013). Defining the language assessment literacy gap: Evidence from a parliamentary inquiry. Language Testing, 30(3), 381-402. https://doi.org/10.1177/0265532213480337

Purtaş, F. (2013). Türk dış politikasının yükselen değeri: Kültürel diplomasi. Gazi Akademik Bakış, 7(13), $1-14$.

Swidler, A. (1995). Cultural power and social movements. In H. Johnston and B. Klandermans (Eds.), Social Movements and Culture (pp. 25-40). New York: Routledge.

Turgut Gültekin, N. \& Uysal, M. (2018). Kültürel miras bilinci, farkındalık ve katılım: Taşkale köyü örneği. OPUS Uluslararası Toplum Araştırmaları Dergisi, 8(15), 2030-2065. https://doi.org/10.26466/opus.446272

Turhan, M. (1994) Kültür değişimleri. İstanbul: Marmara Üniversitesi ilahiyat Fakültesi Vakfı, No: 16.

\begin{tabular}{r|l} 
Adres & Address \\
RumeliDE Dil ve Edebiyat Araşttrmaları Dergisi & RumeliDE Journal of Language and Literature Studies \\
Osmanağa Mahallesi, Mürver Çiçeği Sokak, No:14/8 & Osmanağa Mahallesi, Mürver Çiçeği Sokak, No:14/8 \\
Kadıköy - İSTANBUL / TÜRKIYY 34714 & Kadıköy - ISTANBUL / TURKEY 34714 \\
e-posta: editor@rumelide.com & e-mail: editor@rumelide.com, \\
phone: +90 505 7958124, +90 2167730616
\end{tabular}


UNESCO. (2021). İnsanlğ̆ın somut olmayan kültürel mirası temsilî listesi. https://www.unesco.org.tr/Pages/126/123/UNESCO-\%C4\%Bonsanl\%C4\%B1\%C4\%9F\% C4\%B1n-Somut-Olmayan-K\%C3\%BClt\%C3\%BCrel-Miras\%C4\%B1-Temsil\%C3\%AE-Listesi

Ünveren Kapanadze, D. (2018). Dil ve kültür aktarımında işlevsel bir araç olarak ders kitapları: Türkçe ders kitapları örneği. Turkish Studies Educational Sciences, Volume 13(27), 1575-1592. https://doi.org/10.7827/TurkishStudies.14396

Ylldırım, A. \& Şimşek, H. (2016). Sosyal bilimlerde nitel araştırma yöntemleri. Ankara: Seçkin.

Yıldız, D. \& Ceran D. (2020). 5. ve 7. sınıf Türkçe ders kitaplarında somut olmayan kültürel miras unsurları. SEFAD, (44), 295-308. https://doi.org/10.21497/sefad.845421

YÖK, (2020). Yeni YÖK’ün 2020 yılında hayata geçirdiği yeni projeler ve düzenlemeler. Yükseköğretim Kurulu. YÖK Yeni YÖK'ün 2020 Projeleri ve Düzenlemeleri (yok.gov.tr)

Yüce, K. \& Koçer, Ö. (2014). Yabancı dil olarak Türkçe öğretiminde hedef kültür. (Ed. A. Şahin), Yabancı dil olarak Türkçe öğretimi içinde (ss. 479-490). Ankara: Pegem Akademi.

Wodak, R. (2012). Language, power and identity. Language Teaching, 45(2), 215-233. https://doi.org/10.1017/So261444811000048 